\title{
A
}

Acta HealthMedica

Acta HealthMedica (ISSN: 2414-6528) http://www.ActaHealthMedica.com

Volume 3, Issue 1, February 2018, Pages: 251, DOI: http://dx.doi.org/10.19082/ah251

\section{MOLECULAR DOCKING STUDY OF A NUCLEOTIDASE PURIFIED FROM CERASTES CERASTES VENOM: PROSPECT OF USE IN THE TREATMENT OF CD 73 DEFICIENCY}

Saoud Samah, Chérifi Fatah, Laraba-Djebari Fatima

USTHB, Faculty of Biological Sciences; Laboratory of Cellular and Molecular Biology, BP 32 El Alia, Bab Ezzouar, Algiers, Algeria.

Email address: samah9010@gmail.com,Web: www.usthb.dz

\section{TYPE OF ARTICLE: CONFERENCE ABSTRACT}

\begin{abstract}
Background: Deficiency in ecto- $5^{\prime}$-nucleotidase CD73 alters thromboregulation and affects coronary vascular tone and platelet activation. Previous studies reported that the treatment with soluble $5^{\prime}$ nucleotidase inhibited platelet aggregation and may be clinically beneficial in vascular leakage, myocardial or acute lung injury. Therefore, in this study, we purified and characterized a nucleotidase CD73-like "Cc-5'NTase" from Cerastes cerastes venom.

Methods: The aggregation was explored by induction with the agonists after 5-min of platelet incubation with the purified molecule. Anticoagulant effect of $\mathrm{Cc}^{5}{ }^{5}$ 'NTase was tested by i.p. injection to mice. Cc-5'NTase 3D structure was modeled by homology to a human ecto-2 5'-nucleotiase (4h1S.pdb). Molecular docking was performed using the Glide tool in Schrodinger software.

Results: Cc-5'NTase is a $70 \mathrm{kDa}$ enzyme, structured into $13 \alpha$-helices and $26 \beta$-strands. It displayed anti-platelet and anticoagulant activities that probably involve hydrolysis of ADP, prevention of its binding to $\mathrm{P} 2 \mathrm{Y}$ receptors and the binding of resulting adenosine to its $\mathrm{P} 1$ receptor. Molecular docking study showed that pharmacological effects of Cc-5'NTase were mediated by targeting; ADP via six hydrogen bonds established with Tyr351, Leu573, Tyr288, Ser60 and two with Val265, AMP via six hydrogen bonds established with Asn251, Thr253, His362, Gly448 and two with Arg53 and ATP via five hydrogen bonds established with Asn125, Asn252, Leu192 and two with Arg401 as well as three salt bridges linked with Arg360 and Arg401.

Conclusion: According to these data, $\mathrm{Cc}-5^{5} \mathrm{NT}$ ase could constitute an alternative pharmacological tool to treat pathologies due to the loss of CD73 functions.

KEYWORDS: Nucleotidase, Molecular docking, Anti-platelet, Anticoagulant, Treatment of CD73 deficiency
\end{abstract}

\footnotetext{
Abstracts of Second International Conference on Health Sciences and Medical Technologies, 10-12 October 2017, Tlemcen, Algeria (ICHSMT-17)

(C) 2018 The Authors. This is an open access article under the terms of the Creative Commons Attribution-NonCommercialNoDerivs License, which permits use and distribution in any medium, provided the original work is properly cited, the use is non-commercial and no modifications or adaptations are made.
} 